\title{
Is Upper Gastrointestinal Radiography a Cost-Effective Alternative to a Helicobacter pylori "Test and Treat" Strategy for Patients With Suspected Peptic Ulcer Disease?
}

\author{
Melissa Rich, M.D., James M. Scheiman, M.D., William Tierney, M.D., and A. Mark Fendrick, M.D. \\ Division of Gastroenterology, and Division of General Medicine, Department of Internal Medicine, and \\ Consortium for Health Outcomes, Innovation, and Cost-Effectiveness Studies (CHOICES), University of \\ Michigan School of Medicine, Ann Arbor, Michigan
}

OBJECTIVE: Current clinical consensus supports an initial Helicobacter pylori (HP) "test and treat" approach when compared to immediate endoscopy for patients with suspected peptic ulcer disease. Alternative diagnostic approaches that incorporate upper GI radiography (UGI) have not been previously evaluated. We sought to determine the cost effectiveness of UGI compared to a HP test and treat strategy, incorporating recent data addressing the reduced prevalence of HP, lower cost of diagnostic interventions, and reduced attribution of PUD to HP.

METHODS: Using decision analysis, three diagnostic and treatment strategies were evaluated: 1) Test and Treatinitial HP serology, treat patients who test positive with HP eradication and antiulcer therapy; 2) Initial UGI seriestreat all patients with documented ulcer disease with HP eradication and antiulcer therapy; and 3) Initial UGI series, HP serology if ulcer present - treat ulcer and HP based on diagnostic test results.

RESULTS: The estimated cost per ulcer cured for each strategy were as follows: test and treat, $\$ 3,025$; initial UGI, $\$ 3,690$; and UGI with serology, $\$ 3,790$. The estimated cost per patient treatment were: test and treat, $\$ 498$; initial UGI, $\$ 610$; and UGI with serology, $\$ 620$. When UGI reimbursement was decreased to less than $\$ 50$, the UGI strategies yielded a lower cost per patient treated than the test and treat strategy.

CONCLUSION: At the current level of reimbursement, UGI should not be considered a cost-effective alternative to the HP test and treat strategy for the initial evaluation of patients with suspected peptic ulcer disease. (Am J Gastroenterol 2000;95:651-658. (C) 2000 by Am. Coll. of Gastroenterology)

\section{INTRODUCTION}

Upper abdominal pain is a common symptom complex accounting for an estimated $4-5 \%$ of primary care physician office visits per year (1). Clinical approaches to the management of dyspepsia rely heavily upon history and impression, although a poor correlation exists between patient symptoms and objective findings on diagnostic testing. Thus, the optimal clinical algorithm remains elusive. Because of its prevalence, defining a diagnostic and treatment strategy for individuals with dyspepsia that is clinically effective and economically acceptable is imperative. This is particularly timely, given concerns regarding the high cost of endoscopy and apprehension over the inappropriate use of eradication therapy for individuals infected with Helicobacter pylori (HP) infection without a diagnosis of peptic ulcer disease (PUD).

Dyspeptic symptoms may be caused by a number of underlying etiologies, including PUD, gastroesophageal reflux, nonulcer dyspepsia, and rarely, malignancy. There is strong consensus that patients presenting with dyspepsia and "alarm" symptoms (e.g., weight loss, dysphagia, early satiety, anemia) should be promptly evaluated with endoscopy (2). The approach to the great majority of symptomatic individuals who present without alarm symptoms is less clear. As many underlying diagnoses have overlapping symptoms, it is difficult, without invasive testing, to distinguish among them (3).

In a 1993 evaluation of open-access endoscopy units, $20 \%$ of dyspeptic patients were found to have active PUD unrelated to NSAID use (4). The prevalence of HP infection in those individuals with documented PUD was $90 \%$. However, recent evidence suggests that the incidence of HP infection in individuals with and without PUD is declining, likely because of the declining infection rate and widespread use of antibiotic therapy (5).

For patients with suspected PUD, decision analytic models support initial noninvasive diagnostic strategies as the preferred approach when compared to immediate endoscopy $(6,7)$. HP serology testing (with endoscopy reserved for treatment failures) is the preferred noninvasive approach. In addition to the cost-effectiveness advantage of the test and 
treat approach when compared to endoscopy, the availability and convenience of serological testing make this strategy attractive. However, in the face of declining HP prevalence, the positive predictive value of serological testing declines, raising the issue of whether a objective diagnosis of PUD before eradication therapy is warranted on clinical and economic grounds.

Cost containment efforts and the desire to prescribe HP eradication only to those patients with PUD necessitate the evaluation of UGI as the initial invasive diagnostic test. The ability of UGI to document the presence or absence of PUD may confer a clinical and cost-effective advantage over the test and treat approach by focusing eradication therapy on those individuals most likely to benefit from HP cure. The widespread availability, patient convenience, and relative decreased cost of UGI, as compared to EGD, may make it an appropriate initial diagnostic alternative for patients with suspected PUD. For these and other reasons, UGI use remains high in clinical practice (8).

The performance characteristics of UGI and endoscopy have been compared in randomized prospective studies involving symptomatic patients (9-11). UGI has been shown to accurately identify structural lesions such as stricture, carcinoma, and outlet obstruction, but is less reliable than endoscopy for mucosal lesions such as PUD. The sensitivity of UGI is reported for the diagnosis of PUD over a wide range (0.5-0.9). The shortcomings of UGI include the inability to obtain a tissue diagnosis, which may be used to document active HP infection.

\section{MATERIALS AND METHODS}

We used decision analysis to estimate the clinical and economic impact of three diagnostic and treatment strategies in a cohort of patients with uncomplicated ulcer-like dyspepsia. Details of the decision analytic model have been published elsewhere (6). Strategies evaluated included: 1) Test and treat-initial HP serology, treat HP positives with eradication therapy and ulcer healing therapy (no ulcer test);2) Initial upper GI series - treat all patients with documented ulcers with ulcer healing and HP eradication therapy (no HP test); and 3) Initial upper GI series with HP serology if ulcer present-treat based on diagnostic test results.

Patients were followed in the simulation for up to $1 \mathrm{yr}$, and costs related to diagnostic testing and health care use were determined over that time. This time frame obviated the requirement for discounting of costs.

The model captured resource use, such as physician visits, pharmaceutical use, procedures, and hospitalizations. Direct medical expenditures were calculated from these data. After the initial management encounter, patients moved among different states of health determined by the likelihood of particular clinical events and the effect of certain medical interventions on the natural history of peptic ulcer disease. Each patient was evaluated at 6-wk intervals for $1 \mathrm{yr}$ for the presence or absence of three clinical condi- tions (i.e., recurrent symptoms, HP infection, and active ulcer disease) upon which all further interactions with the medical care system were based.

\section{Study Population}

A cohort of 1000 patients with uncomplicated ulcer-like dyspepsia who were not taking nonsteroidal anti-inflammatory agents (NSAIDs) was entered into the simulation for the analysis. The assumption was made that no prior evaluation for HP had been performed and, likewise, no prior history of PUD documented.

\section{Initial Diagnostic and Therapeutic Interventions}

TEST AND TREAT STRATEGY. All patients in this group underwent qualitative serological testing for HP. Those with evidence of previous or current infection (test positive) received eradication therapy consisting of antisecretory agents and antibiotics for $2 \mathrm{wk}$ and a subsequent 2 wk of antisecretory therapy. Patients who had a negative serology were prescribed standard dose antisecretory therapy for one month. Regardless of HP test results, patients who continued to have symptoms or relapsed after completion of therapy had endoscopy performed.

INITIAL UGI. UGI radiography was performed in the standard fashion. If an ulcer was identified, HP infection was presumed without testing. Patients with PUD received $2 \mathrm{wk}$ of HP eradication therapy (antibiotics and ulcer healing doses of antisecretory therapy) and an additional $2 \mathrm{wk}$ of antisecretory therapy. If UGI was negative for PUD, patients were prescribed a 4-wk course of standard dose antisecretory therapy. Again, patients who continued to have symptoms or relapsed after completion of therapy underwent endoscopy.

INITIAL UGI WITH HP SEROLOGY IF ULCER PRESENT. UGI radiography was performed and patients underwent HP testing only if an ulcer was identified. In the PUD positive patients in whom HP serology was positive, 2 wk of eradication therapy and and additional 2 wk of antisecretory therapy was prescribed. If HP serology was negative and PUD was present, patients received $4 \mathrm{wk}$ of antisecretory therapy at ulcer healing doses. If no ulcer was identified, patients were prescribed $4 \mathrm{wk}$ of standard dose antisecretory therapy. If symptoms were persistent or recurrent, patients underwent endoscopy.

In sum, this model designed to evaluate initial diagnostic testing, treated all patients with antisecretory medications when a nonulcer source of dyspepsia was identified.

\section{Data Sources}

CLINICAL PROBABILITIES. Pertinent clinical data were obtained from a MEDLINE database search and a review of peer-reviewed journals not included in the database. Table 1 displays clinical input probabilities used in the simulation and ranges used in sensitivity analyses. 
Table 1. Clinical and Cost Inputs

\begin{tabular}{|c|c|c|}
\hline Variable & Base Case (Range) & Study References \\
\hline \multicolumn{3}{|l|}{ Clinical probability } \\
\hline Active ulcer disease, $\%$ & $20(5-30)$ & $4,14-21$ \\
\hline H. pylori infection if ulcer is present, $\%$ & $90(60-90)$ & $5,22,23$ \\
\hline H. pylori infection if no ulcer is present, $\%$ & $50(20-60)$ & 12,13 \\
\hline Ulcer healing rate after antisecretory therapy, $\%$ & $90(50-90)$ & $41-43$ \\
\hline H. pylori eradication after antibiotic course (includes compliance), $\%$ & $85(50-90)$ & $28-40$ \\
\hline Recurrent symptom rate with active ulcers, $\%$ & $90(50-90)$ & 16 \\
\hline Recurrent symptom rate with healed ulcers, $\%$ & $10(0-30)$ & 45 \\
\hline Recurrent symptom rate with no ulcer, \%/y & $30(10-70)$ & 56,57 \\
\hline Ulcer recurrence with $H$. pylori infection, $\% / 100$ patient-months & $2.7(2.0-6.6)$ & $22,46-51$ \\
\hline Ulcer recurrence with no infection, $\% / 100$ patient-months & $0.6(0.1-2.0)$ & $52-55$ \\
\hline Serious antibiotic complication per course, $n$ & $0.5(0.1-1.0)$ & $36,39,40$ \\
\hline Sensitivity of qualitative serologic test for $H$. pylori, \% & $90(50-1.00)$ & 24,25 \\
\hline Specificity of qualitative serologic test for $H$. pylori, \% & $95(50-100)$ & 24,25 \\
\hline Sensitivity of upper GI radiography $\%$ & $90(22-91)$ & $9-11$ \\
\hline Specificity of upper GI radiography $\%$ & $90(90-99)$ & $9-11$ \\
\hline Sensitivity of rapid urease test $\%$ & $90(87-98)$ & 26,27 \\
\hline Specificity of rapid urease test $\%$ & $95(89-95)$ & 26,27 \\
\hline \multicolumn{3}{|l|}{ Cost estimates, $\$$} \\
\hline Endoscopy & $\$ 550$ & \\
\hline Upper GI & $\$ 118$ & \\
\hline Rapid urease test & $\$ 25$ & \\
\hline Antisecretory therapy (6-wk course at full dose) & $\$ 17$ & \\
\hline Maintenance antisecretory therapy (per month) & $\$ 11$ & \\
\hline Antibiotic course (includes adverse events) & $\$ 250$ & \\
\hline Qualitative serologic test for $H$. pylori & $\$ 20$ & \\
\hline Urea breath test & $\$ 100$ & \\
\hline Physician office visit (primary care) & $\$ 39$ & \\
\hline Physician office visit (GI) & $\$ 80$ & \\
\hline Hospitalization for ulcer complication with no surgery & $\$ 7,095$ & \\
\hline Hospitalization for ulcer complication with surgery & $\$ 24,081$ & \\
\hline
\end{tabular}

EPIDEMIOLOGY. The base case analysis postulated that $50 \%$ of the cohort entered into the model was infected with HP (12, 13). In concordance with studies of open access endoscopy, $20 \%$ of the cohort had active PUD (14-21). The percentage of patients with active PUD who were infected with HP was assumed to be $90 \%(4,5,22,23)$.

DIAGNOSIS OF HP INFECTION. The qualitative serology test was presumed to have $90 \%$ sensitivity and $95 \%$ specificity $(24,25)$. Rapid urease testing (RUT), performed with endoscopy in persistently symptomatic patients, was assigned $92 \%$ sensitivity and $92 \%$ specificity $(26,27)$.

DIAGNOSIS OF PUD. Endoscopy was presumed to be $100 \%$ sensitive and specific for detection of PUD. Optimal performance characteristics for UGI were obtained from the literature and assumed $90 \%$ sensitivity and $90 \%$ specificity for detection of PUD (9-11). Active ulcer disease was presumed to be symptomatic.

HP ERADICATION THERAPY. Multiple eradication regimens of varying efficacy, cost, and compliance were evaluated. Therapy for eradication of HP was felt to have an impact on ulcer recurrence but not symptom resolution if symptoms were unrelated to PUD. HP eradication rates were estimated at $85 \%$ and ulcer healing was estimated at $90 \%$ (28-43). Reinfection was assumed not to occur after eradication (44). After ulcer healing, $10 \%$ of ulcer related symptoms recurred (45). Ulcer recurrence with and without HP infection were estimated at $2.7 \%$ and $0.6 \%$ per 100 patient-months, respectively, in the base case analysis (22, 46-55).

For those individuals whose symptoms were not due to active ulcer disease, symptoms recurred at the rate of $30 \%$ after a course of antisecretory therapy and required a physician visit $(56,57)$. These patients then underwent endoscopy if not previously performed. Once the absence of an ulcer was documented these patients did not undergo further diagnostic testing and received symptomatic management for the remainder of the simulation. The remainder of patients who did not have symptom recurrence used no further resources.

\section{Cost Inputs}

All diagnostic testing, treatments, and resource use were included in cost calculation up until the time of endoscopy identifying the cause of the dyspepsia. After the diagnosis of PUD was excluded by endoscopy, treatment costs for nonPUD etiologies of dyspepsia were excluded. Costs of a follow-up endoscopy and rapid urease test (RUT) after UGI revealed a gastric ulcer were not included if the patient remained asymptomatic.

Cost calculations of medical resource use were based 


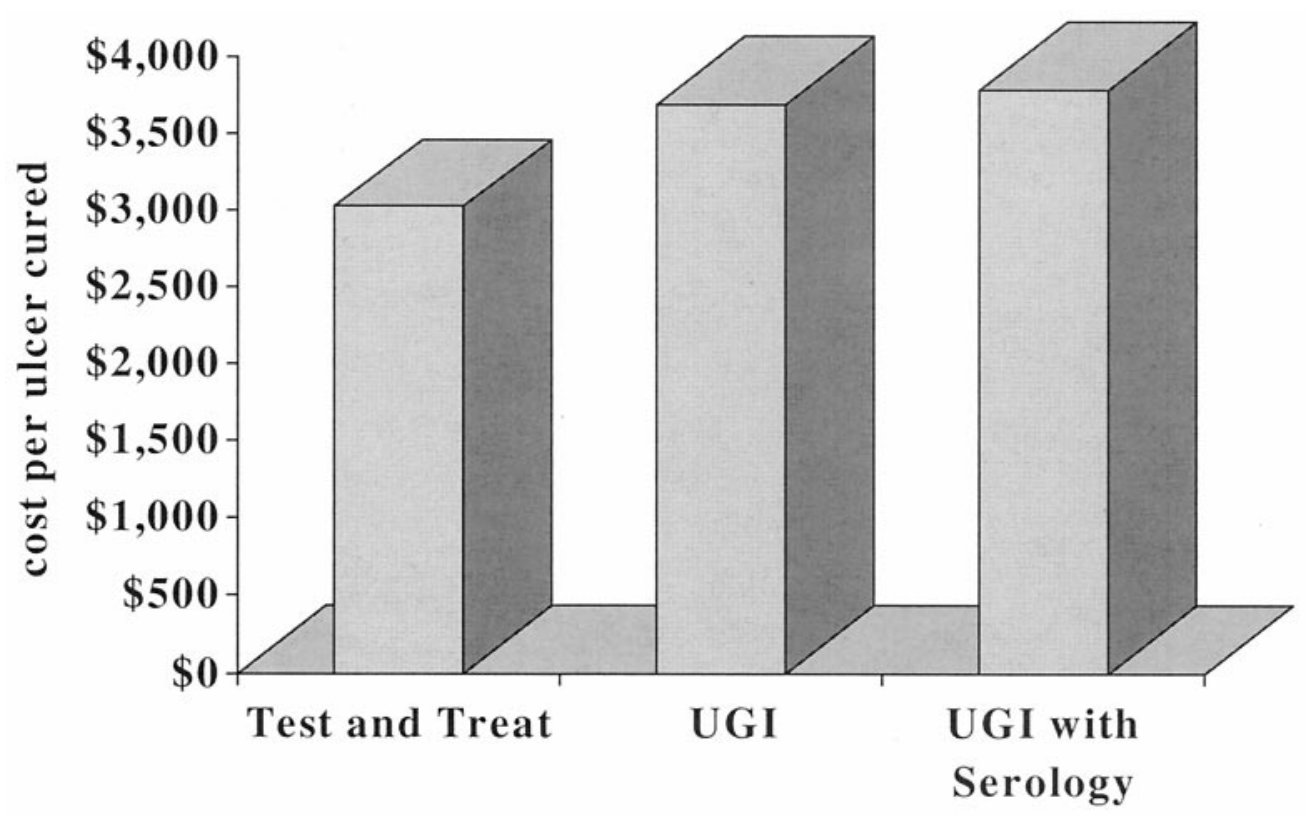

Figure 1. Cost per ulcer cured by management strategy.

upon third party expenditures. Payments, not charges, were used to determine cost estimates. The national average of charges allowed by the Health Care Financing Administration for Medicare reimbursement was used to determine the lower bound of cost estimates, as the payment for similar services varies between geographical regions and delivery systems. The costs of antisecretory therapy (generic H2RA) and HP eradication therapy were obtained from a University hospital pharmacy. Indirect costs to the patient (lost productivity, etc.) were not included in the analysis.

\section{Sensitivity Analysis}

Sensitivity analyses were used to assess the impact of varying clinical and cost inputs over a range reported in the literature. Of note, we varied UGI cost, UGI performance characteristics, and HP prevalence to determine the impact of these key variables on the cost-effectiveness of each strategy.

\section{RESULTS}

\section{Cost Per Ulcer Cured and Cost Per Patient Treated}

In the base case analysis, the estimated treatment cost per ulcer cured for each strategy were: test and treat $\$ 3025$; initial UGI \$3690; and initial UGI with serology \$3790 (Fig. 1). Each strategy led to an equivalent number of symptomatic ulcers cured because of the required endoscopic evaluations for patients with persistent symptoms. The model predicted a lower average cost per patient treated for the test

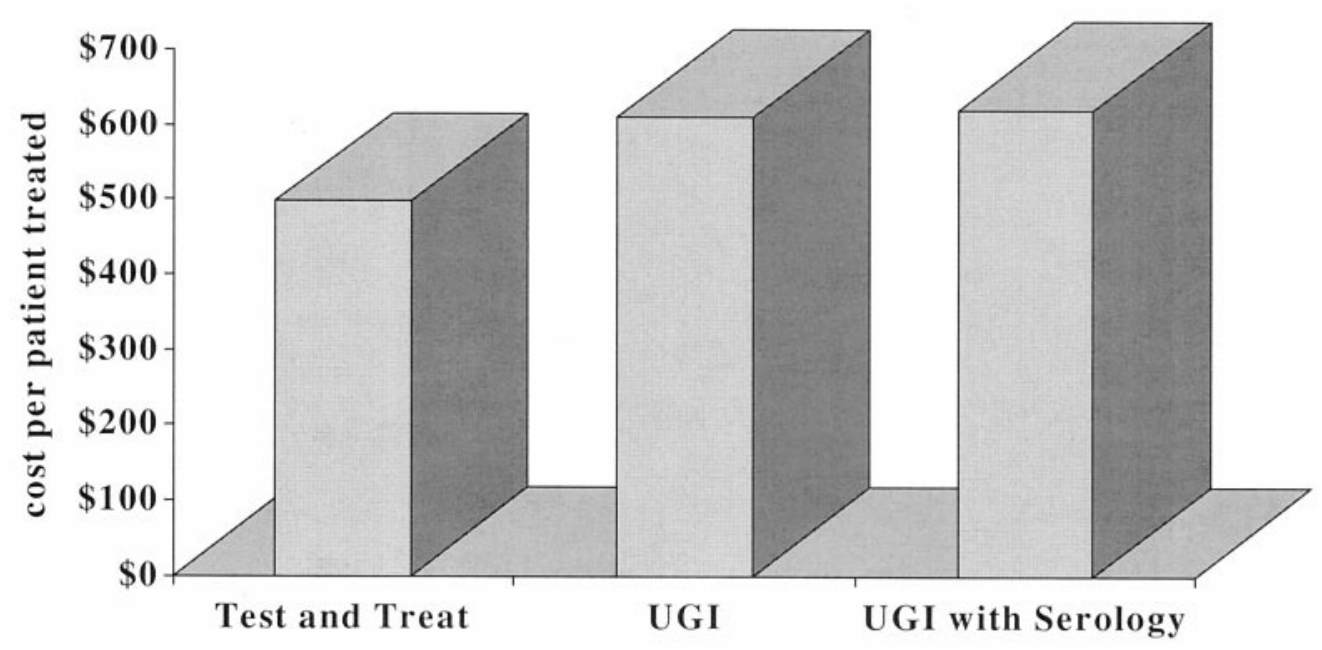

Figure 2. Cost per patient treated by management strategy. 


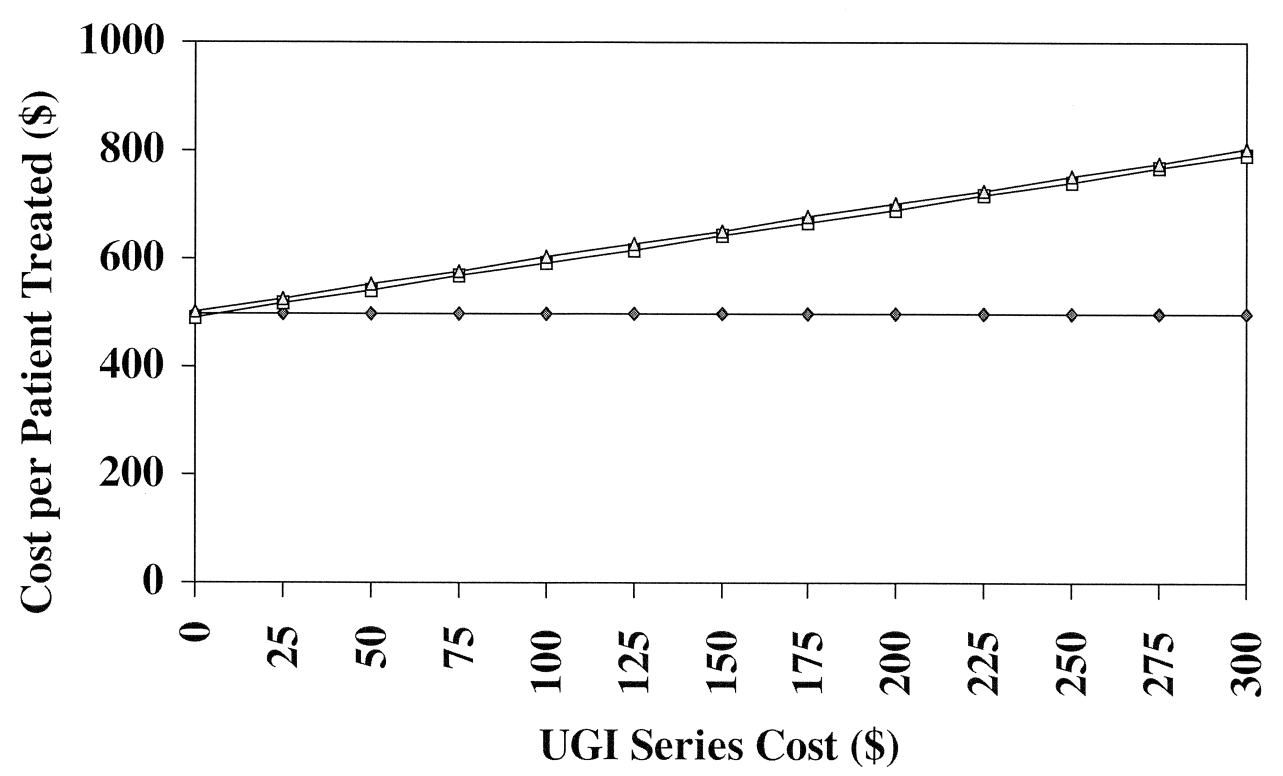

\section{$\rightarrow$ Test andTreat $\quad \rightarrow-$ UGI $\quad \rightarrow$ UGI with Serology}

Figure 3. Sensitivity analysis: cost of upper GI radiography.

and treat strategy (\$498) when compared to UGI (\$610) and UGI with serology (\$620) (Fig. 2).

\section{Sensitivity Analysis}

COST OF UGI. The economic advantage of the test and treat strategy relative to the UGI strategies was sensitive to the cost of UGI. UGI becomes the preferred strategy in terms of cost per patient treated as reimbursement for UGI approached \$50 (Fig. 3).

OPERATING CHARACTERISTICS OF UGI. We varied the sensitivity and specificity of UGI to determine whether there were a combination of performance characteristics at which the UGI strategies would outperform the test and treat strategy on economic grounds. Even when sensitivity and specificity were estimated at $100 \%$, the test and treat strategy continued to yield a lower cost per ulcer cured when compared to UGI strategies (test and treat, \$3177; UGI without serology \$4192; and UGI with serology, \$4363).

HP PREVALENCE. To approximate the evolving epidemiology of HP, we varied the prevalence of HP infection in the entire population while maintaining the proportion of patients with PUD (20\%) and HP-related PUD (90\%). When the HP prevalence in the population was as low as $20 \%$, the economic advantage of the test and treat approach persisted compared to the UGI strategies (test and treat, \$459; UGI without serology, \$623; and UGI with serology, \$633).

We also assessed the impact of the decreased association of HP with PUD (5). While maintaining the ulcer rate at $20 \%$ and population HP prevalence at $50 \%$, we varied the prevalence of HP-associated PUD from $9 \%$ to $90 \%$. Again test and treat strategy provided the lowest cost per patient treated at all HP infection rates (at 9\% prevalence, test and treat, \$485; UGI without serology, \$575; and UGI with serology, \$592). When a worst-case scenario was assumed (HP prevalence 20\% and HP-associated PUD 60\%), test and treat had a lower cost per patient treated when compared to the UGI strategies.

\section{DISCUSSION}

Over the last two decades, identification of Helicobacter pylori has revolutionized the diagnostic approach and treatment of peptic ulcer disease. Simultaneously, cost containment and managed care initiatives have influenced access to and reimbursement for diagnostic tests to document PUD. In 1985, the American College of Physicians (ACP) supported an empiric approach with antisecretory agents to patients with dyspepsia, reserving endoscopy for empiric treatment failures (58). A recent position statement of the American Gastroenterological Association supported a test and treat strategy for those populations in which the prevalence of infection is not universally high and gastric cancer is uncommon (2). In 1994 the NIH Consensus Panel recommended documentation of HP infection in patients with a diagnosis of PUD (either past or present) and subsequent eradication (59). This implicitly embodied endoscopy as the diagnostic test of choice as it would allow accurate and rapid documentation of both diagnoses.

The economic impact of performing endoscopy on all patients presenting with suspected peptic ulcer disease has been previously examined $(6,7)$. Published decision anal- 
yses recommend a test and treat strategy over immediate endoscopy at endoscopy costs greater than $\$ 500$, as the ulcer-related outcomes are similar at a decreased cost per patient. In the test and treat strategy, endoscopy is reserved for those who fail initial serology guided therapy, following ACP guidelines. Randomized controlled trials are underway to compare test and treat strategy versus immediate endoscopy.

Given the concerns regarding over-treatment of HP in patients without PUD and unlikely to benefit from HP eradication, initial diagnostic evaluation of patients with UGI may be an attractive alternative because of low cost, reasonable accuracy, and potential reassurance associated with diagnostic testing. However, the value of diagnostic tests in PUD and the reassurance they offer to patients is unclear (60). A randomized controlled trial comparing UGI versus empiric antisecretory therapy for patients with dyspepsia demonstrated that UGI did not confer a clinical advantage nor did it impact on quality of life measures as measured by the Sickness Impact Profile (61).

Our analyses reveal that test and treat provides similar outcomes and an economic advantage over UGI strategies even when we assumed UGI to be a perfect test for detection of PUD. The cost-effective advantage of test and treat was sensitive to the cost of invasive testing. If the cost of UGI was less than $\$ 50$, UGI would be preferred given similar cost per patient treated, increased diagnostic accuracy, and decreased unnecessary antibiotic use.

As the prevalence of HP infection decreases, increased numbers of patients with false-positive serological tests would receive inappropriate HP eradication therapy. This, in turn, may lead to unnecessary antibiotic associated side effects as well as the increased potential development of antibiotic resistance. Although our model did not assess the societal costs of antibiotic resistance, this consideration will remain prominent, particularly as HP infection rates continue to decline and HP resistance to antibiotics rises (62, 63). However, even at the lowest boundaries of HP prevalence and HP associated PUD the economic advantage of test and treat persisted. Alternatively, our model did not include any benefit of HP eradication other than decreased ulcer recurrence, such as potential reduced risk of gastric carcinoma (64) or ulcer prevention in HP infected individuals without active PUD (65). Inclusion of these potential benefits would further enhance the argument for the test and treat strategy.

In conclusion, for individuals with suspected PUD, the test and treat strategy for HP is preferred when compared to strategies that use UGI initially, at reimbursement rates greater than $\$ 50$. The recommendation to defer definitive ulcer testing on initial presentation was not sensitive to considerations of declining HP prevalence and decreased association of HP to documented PUD. Regardless of initial strategy chosen, it is important to note that endoscopy is indicated in the presence of alarm symptoms and is war- ranted in all patients with persistent symptoms after a single course of therapy.

Reprint requests and correspondence: A. Mark Fendrick, M.D., Division of General Medicine, University of Michigan Medical Center, 3116 Taubman Center, Ann Arbor, Michigan 481090376.

Received June 7, 1999; accepted Dec. 1, 1999.

\section{REFERENCES}

1. Talley NJ, McNeil D, Hayden A, et al. Prognosis of chronic unexplained dyspepsia. A prospective study of potential predictor variables in patients with endoscopically diagnosed nonulcer dyspepsia. Gastroenterology 1987;92:1060-6.

2. Talley NJ, Silverstein MD, Agreus L, et al. AGA technical review. Evaluation of dyspepsia. American Gastroenterological Association. Gastroenterology 1998;114:582-95.

3. Talley NJ, Weaver AL, Tesmer DL, et al. Lack of discriminant value of dyspepsia subgroups in patients referred for upper endoscopy. Gastroenterology 1993;105:1378-86.

4. Mansi C, Mela GS, Savarino V, et al. Open access endoscopy: A large-scale analysis of its use in dyspeptic patients. J Clin Gastroenterol 1993;16:149-53.

5. Laine L, Hopkins RJ, Girardi LS. Has the impact of Helicobacter pylori therapy on ulcer recurrence in the United States been overstated? A meta-analysis of rigorously designed trials. Am J Gastroenterol 1998;93:1409-15.

6. Fendrick AM, Chernew ME, Hirth RA, et al. Alternative management strategies for patients with suspected peptic ulcer disease. Ann Intern Med 1995;123:260-8.

7. Silverstein MD, Petterson T, Talley NJ. Initial endoscopy or empirical therapy with or without testing for Helicobacter pylori for dyspepsia: a decision analysis. Gastroenterology 1996;110:72-83.

8. Schwartz LM, Woloshin S, Welch HG. Trends in diagnostic testing following a national guideline for evaluation of dyspepsia. Arch Intern Med 1996;156:873-5.

9. Martin TR, Vennes JA, Silvis SE, et al. A comparison of upper gastrointestinal endoscopy and radiography. J Clin Gastroenterol 1980;2:21-5.

10. Shaw PC, van Romunde LK, Griffioen G, et al. Peptic ulcer and gastric carcinoma: Diagnosis with biphasic radiography compared with fiberoptic endoscopy. Radiology 1987;163: 39-42.

11. Dooley CP, Larson AW, Stace NH, et al. Double-contrast barium meal, and upper gastrointestinal endoscopy. A comparative study. Ann Intern Med 1984;101:538-45.

12. Dooley CP, Cohen H, Fitzgibbons PL, et al. Prevalence of Helicobacter pylori infection and histologic gastritis in asymptomatic persons. N Engl J Med 1989;321:1562-6.

13. Greenberg RE, Bank S. The prevalence of Helicobacter pylori in nonulcer dyspepsia. Importance of stratification according to age. Arch Intern Med 1990;150:2053-5.

14. Mollmann KM, Bonnevie O, Gudbrand Hoyer E, et al. A diagnostic study of patients with upper abdominal pain. Scand J Gastroenterol 1975;10:805-9.

15. Kagevi I, Lofstedt S, Persson LG. Endoscopic findings and diagnoses in unselected dyspeptic patients at a primary health care center. Scand J Gastroenterol 1989;24:145-50.

16. Jones R, Lydeard S. Prevalence of symptoms of dyspepsia in the community. Br Med J 1989;298:30-2.

17. Horrocks JC, De Dombal FT. Clinical presentation of patients with "dyspepsia." Detailed symptomatic study of 360 patients. Gut 1978;19:19-26. 
18. Fisher JA, Surridge JG, Vartan CP, et al. Upper gastrointestinal endoscopy-A GP service. Br Med J 1977;2:1199-1201.

19. Gear MW, Barnes RJ. Endoscopic studies of dyspepsia in a general practice. Br Med J 1980;280:1136-7.

20. Barnes RJ, Gear MW, Nicol A, et al. Study of dyspepsia in a general practice as assessed by endoscopy and radiology. $\mathrm{Br}$ Med J 1974;4:214-6.

21. Colin-Jones DG. Endoscopy or radiology for upper gastrointestinal symptoms. Lancet 1986;1:1022-3.

22. Rauws EA, Tytgat GN. Cure of duodenal ulcer associated with eradication of Helicobacter pylori. Lancet 1990;335:1233-5.

23. Marshall BJ, Goodwin CS, Warren JR, et al. Prospective double-blind trial of duodenal ulcer relapse after eradication of Campylobacter pylori. Lancet 1988;2:1437-42.

24. Evans DJ Jr, Evans DG, Graham DY, et al. A sensitive and specific serologic test for detection of Campylobacter pylori infection. Gastroenterology 1989;96:1004-8.

25. Talley NJ, Kost L, Haddad A, et al. Comparison of commercial serological tests for detection of Helicobacter pylori antibodies. J Clin Microbiol 1992;30:3146-50.

26. Cutler AF, Havstad S, Ma CK, et al. Accuracy of invasive and noninvasive tests to diagnose Helicobacter pylori infection. Gastroenterology 1995;109:136-41.

27. Murata H, Kawano S, Tsuji S, et al. Evaluation of the PyloriTek test for detection of Helicobacter pylori infection in cases with and without eradication therapy. Am J Gastroenterol 1998;93:2102-5.

28. Bayerdorffer E, Miehlke S, Mannes GA, et al. Double-blind trial of omeprazole, and amoxicillin to cure Helicobacter pylori infection in patients with duodenal ulcers. Gastroenterology 1995;108:1412-7.

29. Chiba N, Rao BV, Rademaker JW, et al. Meta-analysis of the efficacy of antibiotic therapy in eradicating Helicobacter pylori. Am J Gastroenterol 1992;87:1716-27.

30. Coelho LG, Passos MC, Chausson Y, et al. Five-day bismuthfree triple therapy for the eradication of Helicobacter pylori and reduction of duodenal ulcer relapse. Am J Gastroenterol 1991;86:971-5.

31. Hentschel E, Brandstatter G, Dragosics B, et al. Effect of ranitidine and amoxicillin plus metronidazole on the eradication of Helicobacter pylori and the recurrence of duodenal ulcer. N Engl J Med 1993;328:308-12.

32. Hosking SW, Ling TK, Yung MY, et al. Randomised controlled trial of short term treatment to eradicate Helicobacter pylori in patients with duodenal ulcer. Br Med J 1992;305: $502-4$.

33. Labenz J, Gyenes E, Ruhl GH, et al. Amoxicillin plus omeprazole versus triple therapy for eradication of Helicobacter pylori in duodenal ulcer disease: A prospective, randomized, and controlled study. Gut 1993;34:1167-70.

34. Labenz J, Gyenes E, Ruhl GH, et al. Omeprazole plus amoxicillin: Efficacy of various treatment regimens to eradicate Helicobacter pylori. Am J Gastroenterol 1993;88:491-5.

35. Logan RP, Gummett PA, Hegarty BT, et al. Clarithromycin and omeprazole for Helicobacter pylori. Lancet 1992;340:239 (letter).

36. Thijs JC, Van Zwet AA, Oey HB. Efficacy and side effects of a triple drug regimen for the eradication of Helicobacter pylori. Scand J Gastroenterol 1993;28:934-8.

37. Peterson WL, Graham DY, Marshall B, et al. Clarithromycin as monotherapy for eradication of Helicobacter pylori: a randomized, double-blind trial. Am J Gastroenterol 1993;88: 1860-4.

38. Bell GD, Powell K, Burridge SM, et al. Experience with "triple" anti-Helicobacter pylori eradication therapy. side effects and the importance of testing the pre-treatment bacterial isolate for metronidazole resistance. Aliment Pharmacol Therapeut 1992;6:427-35.

39. Farup PG. Compliance with anti-ulcer medication during short-term healing phase clinical trials. Aliment Pharmacol Therapeut 1992;6:179-86.

40. Malfertheiner P. Compliance, adverse events and antibiotic resistance in Helicobacter pylori treatment. Scand J Gastroenterol 1993;196(suppl):34-7.

41. Bamberg P, Caswell CM, Frame MH, et al.. A meta-analysis comparing the efficacy of omeprazole with H2-receptor antagonists for acute treatment of duodenal ulcer in Asian patients. J Gastroenterol Hepatol 1992;7:577-85.

42. Graham DY, McCullough A, Sklar M, et al. Omeprazole versus placebo in duodenal ulcer healing. The United States experience. Dig Dis Sci 1990;35:66-72.

43. Bardhan KD, Bianchi Porro G, Bose K, et al.. A comparision of two different doses of omeprazole versus ranitidine in treatment of duodenal ulcers. J Clin Gastroenterol 1989;21: $408-13$

44. Abu-Mahfouz MZ, Prasad VM, Santogade P, et al. Helicobacter pylori recurrence after successful eradication: 5-year follow-up in the United States. Am J Gastroenterol 1997;92: 2025-8.

45. Archambult AP, Pare P, Bailey RJ, et al. Omeprazole (20 mg daily) versus cimetidine (1200 mg daily) in duodenal ulcer healing, and pain relief. Gastroenterology 1988;94:1130-4.

46. Graham DY, Colon-Pagan J, Morse RS, et al. Ulcer recurrence following duodenal ulcer healing with omeprazole, ranitidine, or placebo: A double-blind, multicenter, 6-month study. The Omeprazole Duodenal Ulcer Study Group. Gastroenterology 1992;102:1289-94.

47. Dobrilla G, Vallaperta P, Amplatz S. Influence of ulcer healing agents on ulcer relapse after discontinuation of acute treatment: a pooled estimate of controlled clinical trials. Gut 1988;29:181-7.

48. Elashoff JD, Van Deventer G, Reedy TJ, et al. Long-term follow-up of duodenal ulcer patients. J Clin Gastroenterol 1983;5:509-15.

49. Glise H, Carling L, Hallerbaeck B, et al. Relapse rate of healed duodenal, prepyloric, and gastric ulcers treated either with sucralfate or cimetidine. Am J Med 1987;83:105-9.

50. Lane MR, Lee SP. Recurrence of duodenal ulcer after medical treatment. Lancet 1988;1:1147-9.

51. Van Deventer GM, Elashoff JD, Reedy TJ, et al.. A randomized study of maintenance therapy with ranitidine to prevent the recurrence of duodenal ulcer. N Engl J Med 1989;320: 1113-9.

52. Bank S, Chow K, Greenberg R. Helicobacter pylori and recurrence of duodenal ulcers. Am J Gastroenterol 1992;87: $1365-7$.

53. Forbes GM, Glaser ME, Cullen DJ, et al. Duodenal ulcer treated with Helicobacter pylori eradication: seven-year follow-up. Lancet 1994;343:258-60.

54. Borody TJ, Cole P, Noonan S, et al. Recurrence of duodenal ulcer and Campylobacter pylori infection after eradication. Med J Australia 1989;151:431-5.

55. Coghlan JG, Gilligan D, Humphries H, et al. Campylobacter pylori and recurrence of duodenal ulcers-A 12-month follow-up study. Lancet 1987;2:1109-11.

56. Patchett S, Beattie S, Leen E, et al. Eradicating Helicobacter pylori and symptoms of non-ulcer dyspepsia. Br Med J 1991; 303:1238-40.

57. Bytzer P, Hansen JM, Schaffalitzky de Muckadell OB. Empirical H2-blocker therapy or prompt endoscopy in management of dyspepsia. Lancet 1994;343:811-6.

58. Anonymous. Endoscopy in the evaluation of dyspepsia. 
Health, and Public Policy Committee, American College of Physicians. Ann Intern Med 1985;102:266-9.

59. Anonymous. NIH Consensus Conference. Helicobacter pylori in peptic ulcer disease. NIH Consensus Development Panel on Helicobacter pylori in Peptic Ulcer Disease. JAMA 1994;272:65-9.

60. Hirth RA, Bloom BS, Chernew ME, et al. Willingness to pay for diagnostic certainty. J Gen Intern Med 1999;14:193-5.

61. Goodson JD, Lehmann JW, Richter JM, et al. Is upper gastrointestinal radiography necessary in the initial management of uncomplicated dyspepsia? A randomized controlled trial comparing empiric antacid therapy plus patient reassurance with traditional care. J Gen Intern Med 1989;4:367-74.
62. Ling TK, Cheng AF, Sung JJ, et al. An increase in Helicobacter pylori strains resistant to metronidazole: A five-year study. Helicobacter 1996;1:57-61.

63. Vakil N, Hahn B, McSorley D. Clarithromycin-resistant Helicobacter pylori in patients with duodenal ulcer in the United States. Am J Gastroenterol 1998;93:1432-5.

64. Fendrick AM, Chernew ME, Hirth RA, et al. Clinical and economic effects of population-based Helicobacter pylori screening to prevent gastric cancer. Arch Intern Med 1999; 159:142-8.

65. Nomura A, Stemmermann G, Chyou PH, et al. Helicobacter pylori infection and the risk for duodenal and gastric ulceration. Ann Intern Med 1994;120:977-81. 